£2-3 per acre. A broad-scale field survey of the Tipperary region in the Northern Territory was completed during the year, and inoculation of pelleted seed with very high numbers of nodule bacteria by a multi-step process has produced up to 100 per cent nodulation of subterranean and crimson clovers sown on skeletal hill soils where the standard commercial inoculation is without effect. A technique has been developed permitting separation of composite particles of silica from a plant without damaging the structure or altering the composition of the particles; detailed studies of the silica from the vegetative and reproductive parts of the mature oat have revealed that the walls of all types of epidermal cells except cork cells are impregnated with silica.

Studies with radioactive phosphorus have shown that roots of Pinus radiata infected with mycorrhizal fungi take up larger amounts of nutrient and suggest that particularly efficient fungi can be selected for inoculating forestry nurseries. Evidence has been obtained that the cellular organelles (mitochondria) associated with the production of adenosine triphosphate in plant tissues of fruits become heavily labelled by the methyl group of methionine, mostly in the lipid fraction, and, in particular, plant sterols and ubiquinone have been isolated and found to be radioactive. The natural enzymatic formation of ironporphyrin complexes is being investigated, and the structure of the anti-fungal compound, pisatin, isolated from infected peas, has boen established as 3-hydroxypterocarpin.

As little as 0.01 per cent of decontaminating proteins have been detected in the protein hormones that control wool growth by zone electrophoresis on starch gel, and the breakdown of metabolic efficiency incurred by vitamin- $B_{12}$ deficiency in sheep has been located in the chomical transformation through which propionic acid is launched into the energy-producing cycle, that is, in the isomeric conversion of the intermediate methylmalonic acid to succinic acid. An investigation of the pyrrolizidone alkaloids occurring in plants indicates that those causing chronic or acute liver damage when eaten by animals have similarities in the structure of their molecules and that their effects on the cell nuclei resemble the effects of the so-called biological alkylating agents. An investigation of the flight behaviour of the Australian plague locust early in 1962 indicated that the occurrence of numerous flying swarms in the 'outbreak areas' is not necessarily a prelude to a widespread outbreak.

A laboratory has been established at Canberra, where the alarm and distress signals of several species of birds have been recorded and prepared for analysis, and where aggressive, territorial, food finding, mating and other calls are being studied in relation to the behaviour and social organization of birds. An infrared design of a single-effect solar still with a plastic base, producing about 10 gal. of distilled water on a clear summer day, at an estimated cost of $£ 1$ per 1,000 gal., is undergoing tests and a prototype for use in isolated areas is being built. The illumination of pedestrian crossings by floodlighting the pedestrians from the directions of the approaching traffic streams has been successfully tested in two experimental installations. Four protein preparations have now been extracted from wool fibre; the two with a high content of sulphur have much smaller molecules than the two with a low content of sulphur and are basic in nature in the original fibre, whereas the lowsulphur proteins are acidic. Ultra-violet radiation in sunlight splits the disulphide bonds of cystine, and chemical investigations of pure cystine suggest that, in presence of air, it is the bond between the carbon and sulphur atoms that is split in neutral and alkaline solutions, whereas in acid solutions the bond between the two sulphur atoms is split.

By spray drying an emulsion of butter fat in a solution of sodium caseinate and non-fat milk solids a new dairy product, powdered butter, has been produced, containing 80 per cent of fat with 15 per cent, of milk protein and some mineral salts, which is more convenient than normal butter for use in cakes, frying batter and ice-cream. A long-term investigation is in progress of the physical factors important in bulk wheat storage, particularly heat and moisture transfers within the bulk. A new humidity-sensitive element, consisting essentially of a thin layer of selenium dioxide, the electrical resistance of which responds to changes in the humidity of the surrounding atmosphere, has been developed with rapid response and good aceuracy even at more than 90 per cent relative humidity and near the freezing point. Completion of the first survey of the distribution of ozone in the southern hemisphere has shown that the distribution differs significantly from that in the northern. hemisphere. Mathematical methods for removing the effect of the spread of energy and greatly reducing the random scatter in ionization investigations have been devised by utilizing certain redundancies in the measured data. An instrument has been devised which measures simultaneously the atmospheric distortion in measurements of the total light from a star, its position and its image.

\title{
UNIVERSITY DEVELOPMENT IN INDIA
}

\begin{abstract}
$\mathrm{T}^{\mathrm{H}}$ HE Statistical Report, 1961-62, on University Development in India*, prepared by the Statistics Section of the University Grants Commission, New Delhi, is based on returns received from the 53 universities recognized in July 1962; of these 15 are unitary, 2 federal and 36 affiliating, while there are 5 other institutions, including the Indian Agricultural Research Institute, New Delhi, and the Indian Institute of Science, Bangalore, deemed to be universities under the University Grants Commission Act

* University Development in India: A Statistical Report, 1961-62 Pp. vii + 76. (New Delhi: University Grants Commission, 1962.) Pp. vii +76. . $5.50 \mathrm{nP}$; 58 .
\end{abstract}

of 1956. The number of teaching departments was 904 , including 233 in science, 80 in medicine, 33 in engineering and 17 in technology, and the total number of students enrolled was 980,380 , of whom 841,580 were in the 1,676 affiliated colleges and 138,800 in the teaching departments: there were also 169,627 women students; these totals represent increases of 13 per eent and 12 per cent, respectively, on the number of students in 1960-61. The Universities of Agra, Bombay, Calcutta, Kerale, Madras and the Punjab together account for $40 \cdot 1$ per cent of the total compared with 41.8 per cent in 1960-61, and 
there are now 6 universities instead of 2 with loss than 1,000 students.

Tho total toaching staff was 54,853, together with 8,200 tutors and demonstrators, giving a staffstudent ratio of $1: 15.5$; slight improvement is notod at Agra, Calcutta and the Punjab, but at Madras and Kerale the ratio has worsened. Students residing in halls of residence numbered 178,423, or 18.2 per cent compared with $17 \cdot 6$ per cent the previous year. Some 72,859 students were engaged in postgraduate/research work compared with 63,000 the previous year. Of the postgraduate students 14,511 were in scienco, with a further 1,876 engaged in research, but for engineering and technology the corresponding figures wore only 418 and 29 and 243 and 17, respectively, and in modicino, 1,841 and 46. Besides an analysis of enrolment trends generally the report roviews the estimates for the Third Year Plan in comparison with the Socond Year Plan, which sets a target of $1,300,000$ students in 58 universities in $1965-66$ and is expected to provide 21,000 postgraduates in scionce, 100,000 engineers and technologists, and some 32,000 in agriculture and allied sciences. Expenditure on research is estimated at 130,000 croros of rupoes, compared with 7,200 under the Second Plan.

\title{
DEMAGNETIZING FIELDS OF INHOMOGENEOUS INDUCED MAGNETIZATION
}

\author{
BY DR. ANDREAS VOGEL \\ Institute of Geodesy, Geophysical Laboratory, UppsalanHällby
}

THE induced magnetization of bodies with constant susceptibility and homogeneous magnetization is described by the following equation:

$$
\bar{J}_{e}=\bar{J}_{0}-x N \bar{J}_{e}
$$

when $J_{\rho}=$ effectivo magnetization; $J_{0}=$ primary magnetization; $x=$ susceptibility; $N=$ domagnotization factor.

Based on the effoct of free magnetic poles on the surface of magnetized bodies $N$ has only boen calonl-

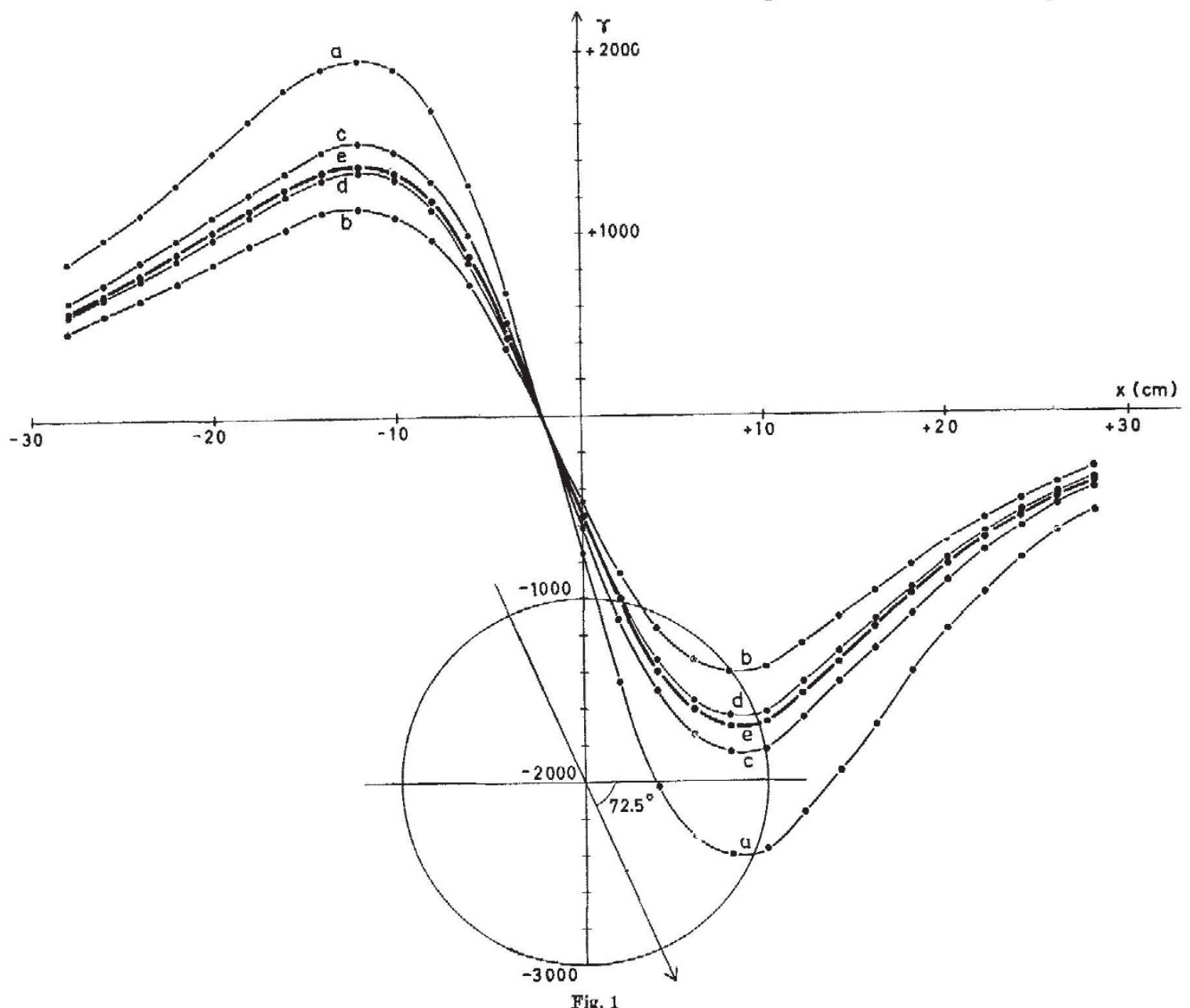

